\title{
Descrição anátomo-radiográfica do esqueleto axial da paca (Agouti paca, Linnaeus, 1766)
}

\author{
Anatomoradiographic description of the axial skeleton of paca (Agouti paca, Linnaeus, 1766) \\ Fabrício Singaretti de Oliveira', Júlio Carlos Canola², Márcia Rita \\ Fernandes Machado \& Mauro Henrique Bueno de Camargo
}

\begin{abstract}
RESUMO
O esqueleto axial compreende o crânio, a coluna vertebral, as costelas e o esterno, e o conhecimento anatômicoradiográfico desses ossos é extremamente importante clínico-cirurgicamente. Esta pesquisa foi desenvolvida com o intuito de melhor conhecer alguns aspectos anátomo-radiográficos do esqueleto axial do segundo maior roedor silvestre da fauna brasileira, a paca, uma vez que não existem informações precisas sobre esses dados na literatura. Foram utilizados seis animais de até um ano de idade (três machos e três fêmeas) e seis animais com mais de um ano (três machos e três fêmeas), pertencentes ao Setor de Animais Silvestres do Departamento de Zootecnia da Faculdade de Ciências Agrárias e Veterinárias, Campus de Jaboticabal, SP. Os animais foram anestesiados e radiografados em decúbito lateral e ventral para descrição do esqueleto axial. Para a descrição anatômica, os ossos do esqueleto axial de quatro animais (um macho e uma fêmea adultos, um macho e uma fêmea filhotes) foram utilizados, além da dissecção de dois animais (um macho adulto e uma fêmea filhote). A paca possui sete vértebras cervicais, 13 vértebras torácicas com 13 pares de costelas, seis vértebras lombares, quatro vértebras sacrais e de sete a nove vértebras caudais. $O$ esterno é composto pela cartilagem do manúbrio, por quatro esternebras, pelo xifoesterno e pela cartilagem xifóide. As pacas são animais compactos, de pequeno comprimento longitudinal e com número de vértebras semelhante à maioria dos roedores de laboratório. Embora pareçam animais de cauda praticamente inexistente, há um número considerável de vértebras caudais.
\end{abstract}

Descritores: anatomia, radiografia, esqueleto axial, paca, Agouti paca.

\section{ABSTRACT}

The axial skeleton is formed by the skull, the spine, the ribs and the sternum, and the anatomoradiographic knowledge of those bones is extremely important clinic and surgically. This researches was developed with the purpose of better know some anatomoradiographic aspects of the axial skeleton of the second biggest wild brazilian rodent, the paca, since there is not many information about those aspects in scientific literature. Six animals up to one year old (three males and three females) and six animals older than one year (three males and three females), belonging to the Sector of Wild Animals of the Animal Science Department at the Faculty of Veterinary and Agrarian Sciences, Campus of Jaboticabal, SP, were used. Animals were anesthetized and $\mathrm{x}$-rayed in lateral and ventral recumbency for description of the axial skeleton. As for the anatomical description, bones of the axial skeleton of four animals (an adult male and female, and a young male and female) were utilized, besides the dissection of two frozen dead animals (an adult male and a young female). The paca presents seven cervical vertebrae, 13 thoracic vertebrae with 13 pairs of ribs, six lumbar vertebrae, four sacral vertebrae and seven to nine caudal vertebrae. The sternum is composed by manubrium, four esternebrae, by the xiphisternum to which a xiphoid cartilage is attached. Pacas are compact animals, with small longitudinal length and with number of vertebrae similar to the most of laboratory rodents. Although they resemble animals of practically nonexistent tail, there is a considerable number of caudal vertebrae.

Key words: anatomy, radiograph, axial skeleton, paca, Agouti paca. 


\section{INTRODUÇÃO}

O esqueleto axial é a parte do esqueleto que compreende o crânio, a coluna vertebral, as costelas e o esterno [4], e é um dos constituintes do aparelho locomotor muito bem descrito em animais domésticos e de laboratório. Entretanto, em espécies selvagens, informações anatômicas ou radiográficas sobre o esqueleto axial são escassas, principalmente em relação aos roedores, como a paca, tornando, dessa forma, bastante difícil a descrição de afecções e interpretação de exames que envolvam esses ossos.

Em pacas (Agouti paca), os poucos relatos sobre o esqueleto axial descrevem que a cabeça dessa espécie é triangular, larga e distendida dos lados, com órbitas protuberantes e localizadas relativamente distal ao plano frontal [5]. Os machos apresentam a cabeça mais achatada e larga, e as fêmeas mais fina e esguia [7]. Em ratos de laboratório (Rattus norvegicus), o crânio é composto por vários ossos, a maioria deles localizado na superfície dorsal e estendendo lateralmente [3].

O objetivo desse trabalho foi descrever, anátomo-radiograficamente, o esqueleto axial de um dos maiores roedores brasileiros, a paca, a fim de comparar com os dados existentes na literatura.

\section{MATERIAIS E MÉTODOS}

Foram utilizados seis animais de até um ano de idade (três machos e três fêmeas) e seis animais com mais de um ano (três machos e três fêmeas), pertencentes ao Setor de Animais Silvestres do Departamento de Zootecnia da Faculdade de Ciências Agrárias e Veterinárias, Campus de Jaboticabal, SP. Os animais foram anestesiados e então radiografados em decúbito lateral e ventral para descrição do esqueleto axial. Para a descrição anatômica, o esqueleto axial de seis peças anatômicas (dois machos adultos, um macho filhote, duas fêmeas adultas e uma fêmea filhote) fixadas e conservadas em formalina a $10 \%$ foram utilizados.

\section{RESULTADOS}

O crânio da paca é triangular e possui maior largura na altura da articulação entre os ossos zigomático e maxilar, os quais são bem evidentes e diferentes dos demais ossos crânios devido à presença de rugosidades ou trabéculas ósseas na superfície lateral. As órbitas são incompletas e localizadas no terço médio entre os ossos occipital e nasal, lateralmente.
Os machos apresentam a cabeça mais larga que a das fêmeas.

Esse roedor selvagem brasileiro possui sete vértebras cervicais, 13 torácicas, seis lombares, quatro sacrais e de sete a nove caudais (Figura 1). As maiores vértebras cervicais são o atlas e o áxis, e as cinco outras vértebras são mais curtas e largas. Os processos espinhosos são curtos e pontiagudos, com exceção do áxis.

Em relação às torácicas, quanto mais caudal for a vértebra, maior é o corpo vertebral. O processo espinhoso da primeira vértebra é praticamente perpendicular e vai se tornando mais oblíquo e menos desenvolvido a partir da segunda vértebra.

As vértebras lombares são bem desenvolvidas, com longos processos transversos, e a terceira, a quarta e a quinta se destacam das demais por apresentam maiores os corpos vertebrais, enquanto a primeira e a sexta vértebras possuem os menores. As vértebras lombares mais caudais são mais largas e apresentam processos transversos maiores e menos oblíquos. $\mathrm{O}$ sacro é estreito e alongado crânio-caudalmente e as vértebras sacrais são fundidas e de comprimento uniforme.

As costelas são formadas por longo eixo, um tubérculo, o qual se articula com os processos transversos das vértebras torácicas, e uma cabeça, a qual se articula com os corpos das vértebras. As regiões mais ventrais do corpo da costela são mais largas que as regiões mais dorsais. As costelas cujas cartilagens costais são conectadas ao esterno são denominadas costelas verdadeiras e correspondem a 11 pares (Figura 2). Os dois pares mais caudais são costelas flutuantes, ou seja, não apresentam comunicação com o esterno; este é alongado e consiste de uma grande cartilagem do manúbrio em forma lanceolada, quatro esternébras e um xifoesterno, ao qual a cartilagem xifóide é articulada.

\section{DISCUSSÃO}

Observou-se que o crânio da paca é triangular e largo. As órbitas são localizadas no terço médio entre os ossos occipital e nasal, lateralmente, o que se assemelha ao relato do autor previamente citado, que reporta as órbitas dessa espécie como localizadas relativamente distal ao plano frontal [5]. Os machos apresentam a cabeça mais larga que as fêmeas [7].

A paca possui sete vértebras cervicais, 13 torácicas, seis lombares e quatro sacrais, assim como o 

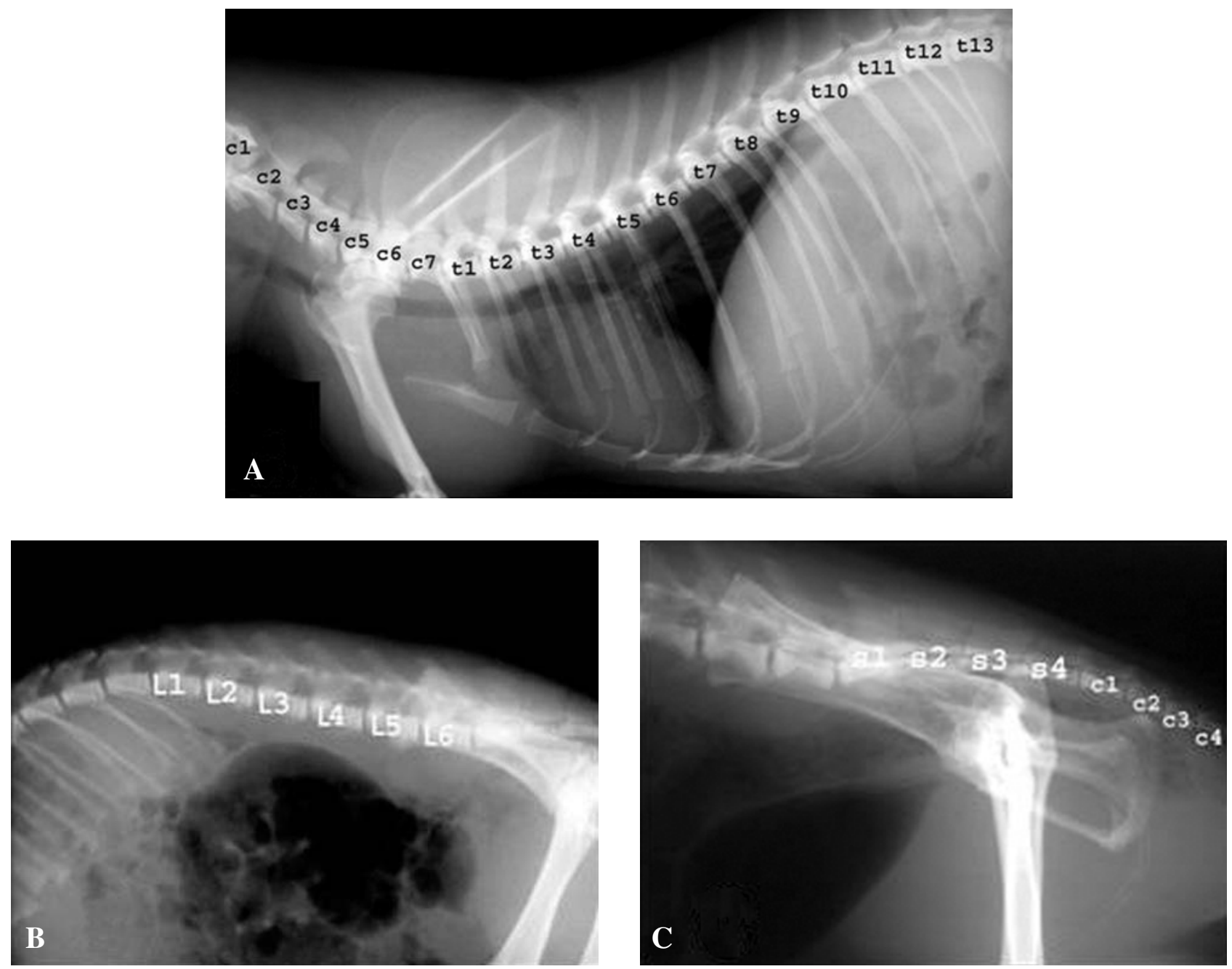

Figura 1. Imagem radiográfica lateral da coluna vertebral da paca. A - vértebras cervicais (c1 a c7) e vértebras torácicas (t1 a t13). B - vértebras lombares (L1 a L6). C - vértebras sacrais (s1 a s4) e caudais (c1 a c4).

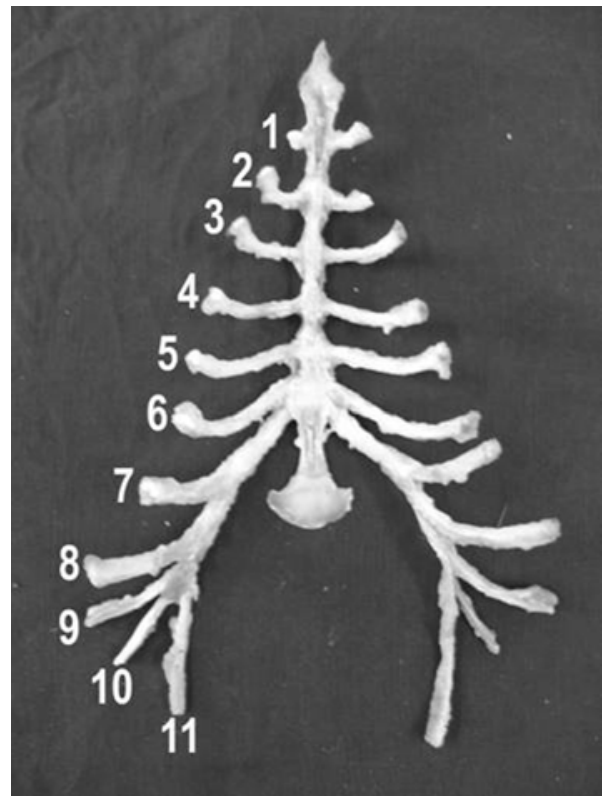

Figura 2. Esterno de paca, evidenciando-se os 11 pares de cartilagens costais que articulam-se às costelas verdadeiras. rato [1,2], o camundongo (Mus musculus), o hamster dourado (Mesocricetus auratus) e o cobaio (Cavia porcellus), e diferentemente do chinchila (Chinchilla lanigera) apenas por este possuir uma vértebra torácica a mais [6]. Possui, ainda, de sete a nove vértebras caudais, diferindo do cobaio, hamster dourado e chinchila, os quais possuem, em média, cinco, 11 e 21 vértebras, respectivamente.

Assim como no rato, as maiores vértebras cervicais da paca são o atlas e o áxis, e as cinco outras vértebras são mais curtas e largas. Os processos espinhosos são curtos e pontiagudos, com exceção do áxis [2].

Quanto às vértebras torácicas, quanto mais caudais forem, maiores são os corpos vertebrais, assim como as dos ratos. Em relação às vértebras lombares, estas não apresentam uniformidade no tamanho, como o ocorrido nos ratos [1], pois a terceira, a quarta e a quinta vértebras lombares se destacam das demais 
por apresentarem maiores corpos vertebrais, enquanto a primeira e a sexta vértebras possuem os menores.

Cada costela é formada por longo eixo, um tubérculo e uma cabeça, a qual se articula com os corpos das vértebras torácicas e os tubérculos são articulados com os processos transversos dessas vértebras, como nos ratos [1].

Na paca há 11 pares de costelas verdadeiras e dois pares de flutuantes; o esterno é alongado e consiste de uma cartilagem do manúbrio, quatro esternébras e um xifoesterno, ao qual a cartilagem xifóide é articulada, como ocorre no rato [1].

\section{CONCLUSÕES}

As pacas são animais compactos, de pequeno comprimento longitudinal e com número de vértebras semelhante à maioria dos roedores de laboratório. Embora pareçam animais de cauda praticamente inexistente, há um número considerável de vértebras caudais (sete a nove).

\section{REFERÊNCIAS}

1 Calam A. \& Baker N. 2001. Disponível em <http://137.222.110.150/calnet/ratskele/_ratskele.htm>. Acessado em 05 jan 2006.

2 Hebel R. \& Stromberg M.W. 1986. Osteology. In: Anatomy and Embryology of the Laboratory Rat. Wörthsee: Biomed Verlag, pp. 9-21.

3 Heithaus P.A. 2005. Disponível em <http://biology.kenyon.edu/courses/biol09/Rat/welcome.htm>. Acessado em 06 jan 2006.

4 König H.E. \& Liebich H-G. 2002. Esqueleto axial. In: Anatomia dos Animais Domésticos: Aparelho Locomotor. Porto Alegre: Artmed, pp. 29-98.

5 Mondolfi E. 1972. La laca o paca. Defensa de la Naturaleza. 2: 4-16.

6 Silverman S. \& Tell L.A. 2005. Radiology of Rodents, Rabbits and Ferrets: An Atlas of Normal Anatomy and Positioning. St. Louis: Elsevier. 299p.

7 Smythe N. 1991. Paca. In: Robinson J.G.\& Redford K.H. (Eds). Microlivestock: Little Known Small Animals with Promising Economic Future. Washington: National Academy. pp.263-269. 